\title{
Vibrational Analysis of Coconut Fiber-PP Composites
}

\author{
Maria Virginia Gelfuso, Daniel Thomazini*, Júlio César Silva de Souza, José Juliano de Lima Junior
}

\author{
Mechanical Engineering Institute, Itajubá Federal University - UNIFEI, \\ Av. BPS, 1303, CEP 37500-903, Itajubá, MG, Brazil
}

Received: April 06, 2013; Revised: November 16, 2013

\begin{abstract}
Many researchers have been studying coconut fibers due to its being a natural and renewable source. Moreover, coconut waste is discarded in landfills, bringing environmental problems because this material, although natural, takes time to be degraded. The use of natural fibers such as coconut fibers has become industrially attractive because of its low cost, high availability and desired mechanical properties for some applications, such as panels, ceilings, and partition boards and automotive components. In this study, polymers with coconut fiber composites were made by injection processing and mechanically characterized by tensile and dynamic testing. The fiber content ranged from 0 to $30 \mathrm{wt} \%$. The results of Young's modulus obtained from both methods decreased with fiber load and were nearly identical up to $15 \mathrm{wt} \%$ of fiber, about $1.1 \mathrm{GPa}$, but the increase in fiber concentrations distinctly interferes with each method in the values obtained.
\end{abstract}

Keywords: vegetal fiber, composite, injection molding, recycling, non destructive test

\section{Introduction}

Natural fibers composites present some advantages over other composites like low-cost and malleability ${ }^{1}$. Monteiro et al. ${ }^{2,3}$ observed that the coconut fibers do not contribute to enhance the mechanical properties of composite based on these fibers. However, the mechanical strength of these materials is high enough to be used in nonstructural elements, such as fence panels and linings. These advantages are sufficient and necessary for construction industries such as panels, ceilings ${ }^{4}$, and partition boards and automotive components ${ }^{5}$. Moreover, some applications involve static or dynamic mechanical stress, which is required to characterize some of these properties, such as modulus, damping factor, among others related to viscoelasticity of materials.

Viscoelastic materials are a class of material that presents viscoelastic rheology, or in other words, which undergoes simultaneously elastic and viscous deformation ${ }^{6}$. Thus, viscoelastic materials present intermediate behavior between pure elastic and plastic deformations, and when harmonic mechanical deformation is applied, neither strain and stress are in phase (as in elastic behavior) nor are phases shifted by $90^{\circ}$ (as a perfect viscous solution), but are among these values ${ }^{7}$. Furthermore, when viscoelastic materials are deformed not all energy in this process will be converted into deformation; some of this energy is used to overcome the internal friction of the material. According to Zener and Siegel $^{8}$, the internal friction is the generic denomination for the energy dissipation effects, which are generated due to the inhomogeneity material. This energy is converted into heat and for high values of deformation some energy could be stored in the material.

*e-mail: ielthom@gmail.com
In literature, there are many methods to determine the dynamic properties of the viscoelastic materials ${ }^{9}$. The Power Input method is based on energy lost in the maximum deformation in a system under steady vibration. The decay answer method is based on the amplitude decay time of a system, imposed by a mass-impact or a shaker. The halfpower band method is based on the measurements of the bandwidth of the frequency between the points in the curve of frequency, taking into account that values are some fractions of the resonance of the system ${ }^{10}$.

Usually, the increase in the damping rate is applied to reduce the mechanical vibrations on structures. Other studies analyze the use of alternative materials with damping properties ${ }^{11}$. These materials applied on surface of structures presenting the same behavior attenuation of vibrations can decrease the total displacement of the system. Materials with viscoelastic properties have been used as dissipation energy elements, promoting the reduction in the vibration levels of rigid structures ${ }^{12}$.

The aim of this study was to characterize the viscoelastic properties of composites based on polypropylene matrix with different amounts of coconut fibers by measuring damping factor, loss factor, storage modulus, loss modulus and complex modulus based on experimental and mathematical calculations as previously described. Values of elastic modulus obtained from standard test stress-strain of composite samples were also obtained in order to compare and validate these results. The viscoelastic measurements were carried out using a laser vibrometer, which represents an excellent choice for performing non-destructive testing, that in many cases is important to maintain the integrity of the samples for further analyses. 


\section{Experimental Procedure}

\subsection{ASTM standard method}

This method is based on E756 - American Society for Testing and Materials - ASTM, as the main method to measure the damping vibration properties of the materials ${ }^{13}$. A beam with predefined dimensions, fixed in one of its ends while the other is free, composes the set used in this procedure.

\subsection{Half-powder band method}

The half-power band method is based on the points related to the half-power to define the damping of the system. This method ${ }^{14}$ gives estimation of the damping rate for system with damping lower than 0.05. According to Silva ${ }^{15}$, this method is one of the most reliable among the others to measure low damping factor systems.

The procedure is based on determining the frequencies in the points $Z_{1}$ and $Z_{2}$ (Figure 1) located in the answer curve, $3 \mathrm{~dB}$ below the maximum amplitude. The bandwidth between these points is the frequency known as 'half-power band' ${ }^{10}$.

The points of half-power to small damping are related to the frequencies represented by Equations 1 and 2 .

$\omega_{1}=\omega_{n}(1-\zeta)$

$\omega_{2}=\omega_{n}(1+\zeta)$

Where $\omega_{1}$ and $\omega_{2}$ are the frequencies associated to the $Z_{1}$ and $Z_{2}$ points, $\zeta$ is the damping factor and $\omega_{n}$ is the natural frequency of the system. The values of $\omega$ are given in $[\mathrm{rad} / \mathrm{s}]$, and $f[\mathrm{~Hz}]$ is the frequency value in SI units.

The interval frequency between these points, in other words, the bandwidth is given by:

$\Delta \omega=\omega_{2}-\omega_{1}$

and the loss factor $(\eta)$, for small damping factors, is defined as:

$\eta=\frac{\Delta \omega}{\omega_{n}}$

The logarithmic decrease $(\Delta)$ can be obtained by peak half-power method, as shown in Equation 5:

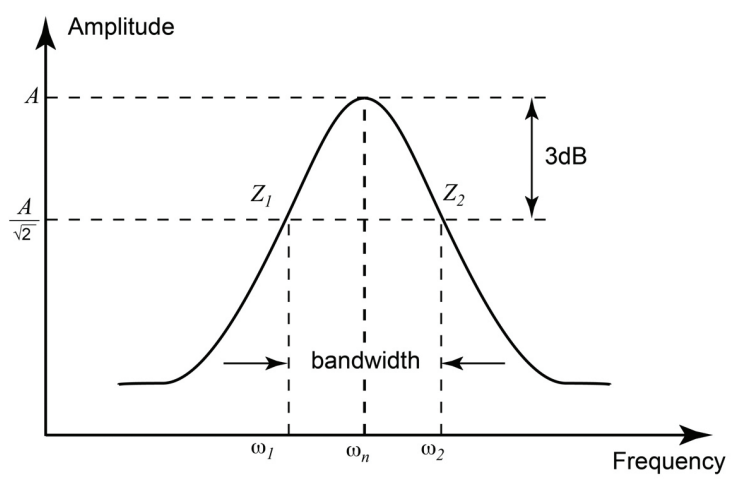

Figure 1. Half-power band method.
$\Delta=\frac{\pi\left(\omega_{2}-\omega_{1}\right)}{\omega_{n}}$

According to the physical and geometric properties of the structure, associated to the concepts of mechanical vibrations ${ }^{16}$, the storage modulus $\left(E^{\prime}\right)$ can be defined by the Equation 6:

$E^{\prime}=\left[\left(\frac{4 \pi^{2} f_{n}^{2}}{3 I}\right)\left(\frac{33 m}{140}\right)\left(1+\frac{\Delta^{2}}{4 \pi^{2}}\right)\right] L^{3}$

Where $I$ is the inertia momentum of the transversal section, $m$ is the mass and $L$ is the length of the beam.

$\mathrm{RaO}^{14}$ defined that the damping factor of a beam is given by Equation 7:

$\zeta=\frac{\omega_{2}-\omega_{1}}{2 \omega_{n}}$

When $\Delta<<1$, it means that $\zeta \cong \frac{\Delta}{2 \pi}$. Rewriting as proposed by Rosen ${ }^{17}$ :

$\eta \approx 2 \zeta$, on the other hand, the loss factor can be written as $\eta=\frac{\Delta}{\pi}=\frac{E^{\prime \prime}}{E^{\prime}}$, so

The dynamic modulus is given by Equation 9:

$E=E^{\prime}(1+i \eta)=E^{\prime}+i E^{\prime \prime}$

In Equation 9, $E^{\prime} \eta$ is related to the viscous energy loss in each cycle of vibration. $E$ " is defined as loss modulus.

$E$ ' and $E$ " can be experimentally defined. Both are excitation frequency and temperature dependents. The procedures should be conducted in a frequency interval and constant temperature, or, in a temperature interval and constant frequency.

\subsection{Composite preparation}

Figure 2 shows the physical aspect of the coconut fiber mat at different steps of the composites preparation. These mats were washed ten times in distilled water at $25{ }^{\circ} \mathrm{C}$ for 5 minutes each, with hand stirring to remove the natural salinity and dust present in the mat. Several coconut fiber mats (Figure 2a) were cut out, stacked, and uniaxially pressed just to shape a coir box (Figure 2b). After that, this coir box was placed inside a mold to perform the PP injection and produce the composite (Figure $2 \mathrm{c}$ ). The thermoplastic polymer polypropylene (PP), used as matrix material, was supplied by Braskem S.A. (São Paulo-Brazil) in the form of homopolymer pellets. It presents $0.90-0.91$ of specific gravity, $165-171{ }^{\circ} \mathrm{C}$ to melting temperatures and $82 \%$ of crystalline phase.

Composite boxes based on coconut fiber-polypropylene containing up to 30 vol\% of coir fibers, as described in Table 1, were formed by injection molding. A HAITIANSA2500/1000B injection machine was used so that a 105.7 $\mathrm{MPa}$ pressure at $175{ }^{\circ} \mathrm{C}$ was applied to inject the boxes. For all tests, specimens were cut out from the bottom of the boxes with a jigsaw and the parallelism of cut edges 


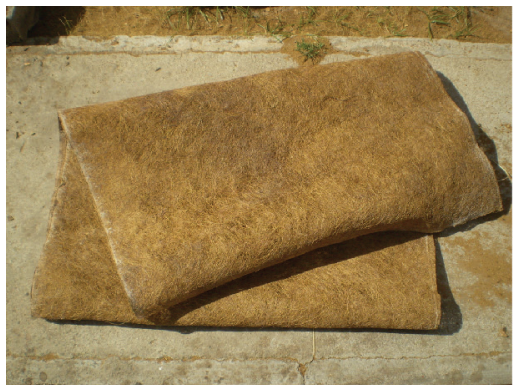

(a)

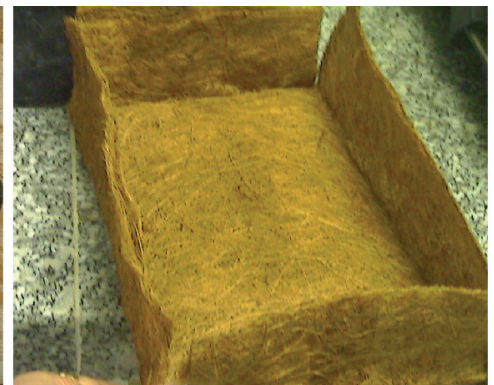

(b)

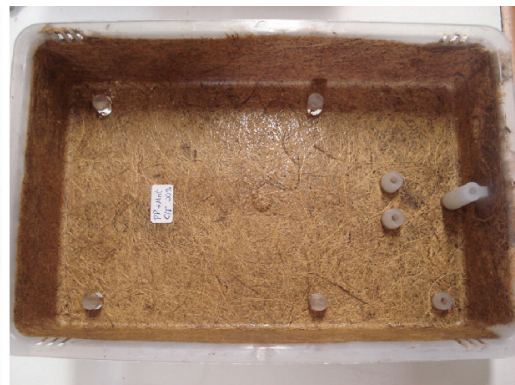

(c)

Figure 2. Physical aspect of the mat at different steps of the composites preparation. a) Raw mat; b) Box-shaped mat; and c) PP-Fiber composite injected.

Table 1. Specimens composition based on filler load.

\begin{tabular}{ll}
\hline \multicolumn{1}{c}{ Sample } & \multicolumn{1}{c}{ Material } \\
\hline $0 \% \mathrm{FC}$ & Pure Polypropylene - PP \\
$5 \% \mathrm{FC}$ & Polypropylene with $5 \mathrm{wt} \%$ of CF \\
$10 \% \mathrm{FC}$ & Polypropylene with $10 \mathrm{wt} \%$ of CF \\
$15 \% \mathrm{FC}$ & Polypropylene with $15 \mathrm{wt} \%$ of CF \\
$20 \% \mathrm{FC}$ & Polypropylene with20wt $\%$ of CF \\
$25 \% \mathrm{FC}$ & Polypropylene with25wt $\%$ of CF \\
$30 \% \mathrm{FC}$ & Polypropylene with30wt $\%$ of CF \\
\hline
\end{tabular}

FC - Fiber content. CF-Coconut fiber.

was obtained through sanding aided by a sandpaper $320 \#$. This region was chosen due to the better fiber homogeneity observed in this specific portion in the box. The physical and geometrical properties of the specimens submitted to the dynamic tests are shown in Table 2.

\subsection{Stress-strain testing}

Tensile tests were performed using an Instron-Model 4484, in accordance to ASTM D638-10. The displacement of the sample was measured with a $50 \mathrm{~mm}$ extensometer. The specimens were tested at a transversal displacement rate of $5 \mathrm{~mm} / \mathrm{min}$, at room temperature. Young's modulus and the tensile strength were obtained from the typical stress-strain curves.

\subsection{Dynamic tests}

To determine the dynamic characteristics of the composites, free vibration tests were performed according to ASTM E756-05. Five beams of each fiber content in weight percentage $(\%$ FC) composite about $160.0 \times 20.0 \times 3.0 \mathrm{~mm}$ $(\mathrm{L} \times \mathrm{B} \times \mathrm{H})$ were submitted to the action of an impulsive force applied to its free ends. Laser vibrometer (Figure 3) was used to measure the displacement in time of the free end of the beam. Oscillatory movements from a pendulum with a sphere at the end were applied as impulsive force source.

The signal analyzer Stanford Research Systems, model SR780, was used to obtain and analyze the frequency spectrum from the oscillatory movements of the free end of the beam. The measurements were performed at $20^{\circ} \mathrm{C}$ and relative humidity of $74 \%$.

\section{Results and Discussions}

Figure 4 shows the aspect of the beams used in dynamic test. The increase of coconut fiber content from PP pure samples to the $30 \% \mathrm{FC}$ samples can be seen.

The natural frequency, logarithmic decrease, damping and loss factor values of the specimens are presented in Table 3. These experimental values were used to calculate the values presented in Table 4, as discussed in the Experimental Procedure section.

Table 4 shows the storage $\left(E^{\prime}\right)$, loss ( $\left.E^{\prime \prime}\right)$ and complex $(E)$ modulus obtained from Equations 6 and 9, and the Young Modulus obtained from stress-strain test $\left(E_{s s}\right)$. Comparing the values of $\mathrm{E}$ and $E_{s s}$ (Figure 5), an equality of the values for pure PP samples, and a small difference of values in samples containing fiber addition up to $15 \% \mathrm{FC}$ can be seen. Above $20 \%$ FC the values are more distinct, and this fact can be associated to the inhomogeneity of the fiber dispersion on the polymeric matrix that can lead to high variation in the results. Also, when the fiber contents increases in the polymeric matrix, the interaction between the fibers also increases, reducing the fiber/matrix interaction $^{18}$, consequently reducing the reinforcement of the matrix. Furthermore, it's noticed that $E$ and $E_{s s}$ values of pure PP are higher than those for $\mathrm{PP} /$ coconut composite. This behavior was also observed in Polyester/coconut composites $^{19}$, associated to low interfacial strength between matrix and fiber, reducing the stress transference from the matrix to the fibers. This behavior is not observed in PP/ glass fiber composites ${ }^{20}$ due to high adhesion that leads to low slip between matrix and fibers.

The curve presented in Figure 6 shows the behavior of loss factor as a function of coconut fiber content. The loss factor is associated to the damping characteristic of the material, and the balance between elastic and viscous phase. Performing average and standard deviation calculations in the loss factor results, it is noticed that these values are $5.4 \pm 0.4 \%$, same values observed for polyester/coconut composites $^{19}$ at room temperature. Monteiro et al. ${ }^{19}$ also observed this effect and the authors associated this behavior to the fact that the coconut fiber supports partially the stress and some deformation of fiber/matrix interface. In this way, the energy loss is related to the interaction between the matrix and the fibers, or, in other words, if the interface is more resistant, the energy dissipation is reduced. 
Table 2. Physical and geometrical properties of the specimens.

\begin{tabular}{|c|c|c|c|c|c|}
\hline Sample & $\mathbf{L}[\mathbf{m m}]$ & B [mm] & $\mathbf{H}[\mathbf{m m}]$ & $\mathbf{I}\left[\mathbf{m}^{4}\right]$ & Weight[g] \\
\hline $0 \% \mathrm{FC}$ & 160 & 20.00 & 3.00 & $4.96 \times 10^{-11}$ & 9.60 \\
\hline $5 \% \mathrm{FC}$ & 160 & 16.00 & 3.00 & $3.60 \times 10^{-11}$ & 8.24 \\
\hline $10 \% \mathrm{FC}$ & 160 & 20.00 & 3.00 & $4.96 \times 10^{-11}$ & 10.04 \\
\hline $15 \% \mathrm{FC}$ & 160 & 17.40 & 3.00 & $4.32 \times 10^{-11}$ & 8.89 \\
\hline $20 \%$ FC & 160 & 17.30 & 3.00 & $4.29 \times 10^{-11}$ & 8.95 \\
\hline $25 \% \mathrm{FC}$ & 160 & 18.30 & 3.00 & $4.54 \times 10^{-11}$ & 9.80 \\
\hline $30 \% \mathrm{FC}$ & 160 & 15.30 & 3.00 & $3.80 \times 10^{-11}$ & 8.77 \\
\hline
\end{tabular}

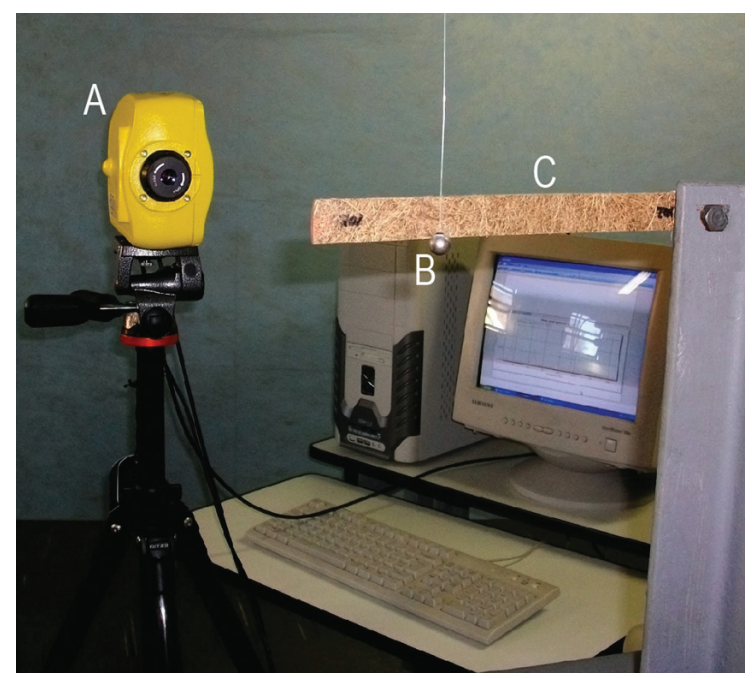

Figure 3. Measurement system composed by A) vibrometer, B) pendulum and C) beam.

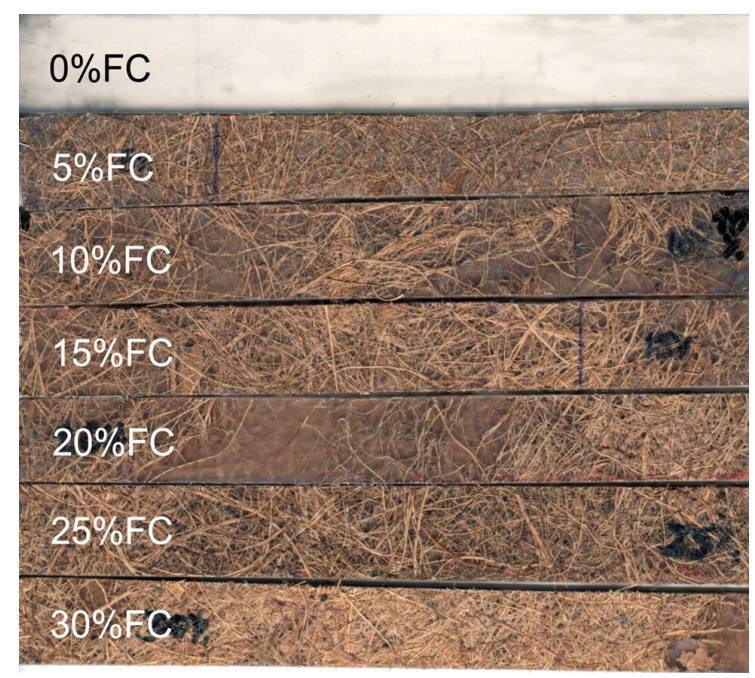

Figure 4. Coconut fibers-PP composites aspect used in dynamic tests.

Table 3. Experimental values obtained from dynamic tests.

\begin{tabular}{|c|c|c|c|c|}
\hline Sample & $f_{n}[\mathrm{~Hz}]$ & $\Delta$ & $\zeta$ & $\eta$ \\
\hline $0 \% \mathrm{FC}$ & 25.08 & 0.173 & $2.8 \times 10^{-2}$ & $5.6 \times 10^{-2}$ \\
\hline $5 \% \mathrm{FC}$ & 22.21 & 0.164 & $2.6 \times 10^{-2}$ & $5.2 \times 10^{-2}$ \\
\hline $10 \% \mathrm{FC}$ & 23.04 & 0.187 & $2.9 \times 10^{-2}$ & $5.8 \times 10^{-2}$ \\
\hline $15 \% \mathrm{FC}$ & 22.41 & 0.166 & $2.6 \times 10^{-2}$ & $5.2 \times 10^{-2}$ \\
\hline $20 \% \mathrm{FC}$ & 22.85 & 0.162 & $2.5 \times 10^{-2}$ & $5.0 \times 10^{-2}$ \\
\hline $25 \% \mathrm{FC}$ & 20.21 & 0.188 & $3.0 \times 10^{-2}$ & $6.0 \times 10^{-2}$ \\
\hline $30 \% \mathrm{FC}$ & 20.00 & 0.161 & $2.5 \times 10^{-2}$ & $5.0 \times 10^{-2}$ \\
\hline
\end{tabular}

Table 4. Natural frequency $\left(f_{n}\right)$, storage $\left(E^{\prime}\right)$, loss $\left(E^{\prime \prime}\right)$, complex modulus $(E)$ and Young modulus from stress-strain tests $\left(E_{s s}\right)$.

\begin{tabular}{|c|c|c|c|c|c|}
\hline Samples & $f_{n}[\mathrm{~Hz}]$ & $E^{\prime}[\mathrm{MPa}]$ & $E$ " $[\mathrm{MPa}]$ & $E[\mathrm{MPa}]$ & $E_{s s}[\mathrm{MPa}]$ \\
\hline $0 \% \mathrm{FC}$ & 25.08 & 1269 & 70 & $1270 \pm 13$ & $1276 \pm 42$ \\
\hline $5 \% \mathrm{FC}$ & 22.21 & 1161 & 60 & $1162 \pm 12$ & $1148 \pm 40$ \\
\hline $10 \% \mathrm{FC}$ & 23.04 & 1121 & 66 & $1122 \pm 11$ & $1100 \pm 36$ \\
\hline $15 \% \mathrm{FC}$ & 22.41 & 1078 & 57 & $1080 \pm 11$ & $1092 \pm 23$ \\
\hline $20 \%$ FC & 22.85 & 1135 & 58 & $1136 \pm 11$ & $1006 \pm 34$ \\
\hline $25 \% \mathrm{FC}$ & 20.21 & 900 & 54 & $901 \pm 9$ & $1008 \pm 29$ \\
\hline $30 \% \mathrm{FC}$ & 20.00 & 856 & 44 & $857 \pm 8$ & $978 \pm 25$ \\
\hline
\end{tabular}




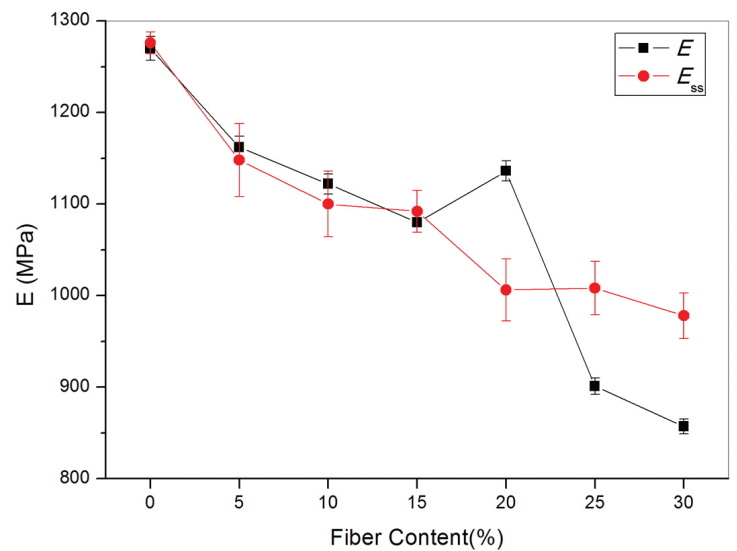

Figure 5. Elastic modulus ( $E$ and $E_{s s}$ ) versus fiber content.

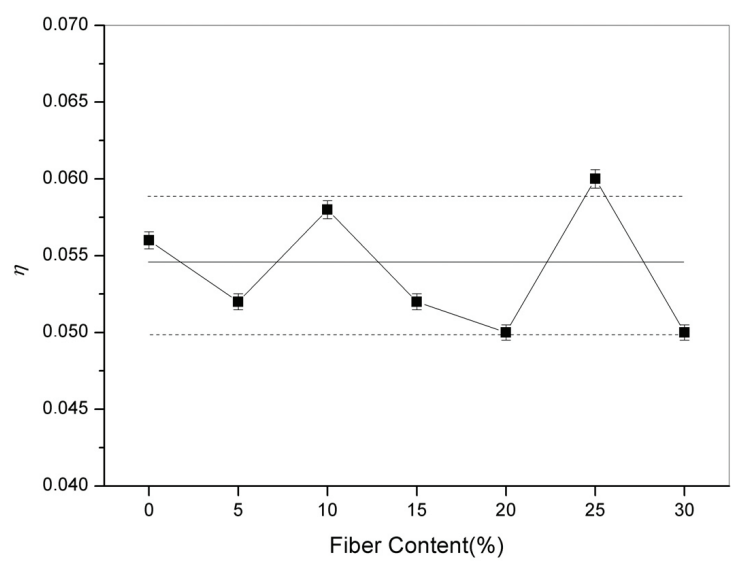

Figure 6. Loss factor as a function of coconut fiber content.

The storage (Figure 7) and loss modulus (Figure 8) were reduced with the increase in coconut fiber content in the composite. In general, the storage modulus is much higher than the loss modulus which leads the main influence on $E$ calculations, according to Equation 9. These results indicate that the coconut fiber reduces the viscoelastic stiffness of the composite. The low elastic modulus of the coconut fiber, compared to PP, is the main contribution to this behavior, as also observed by Monteiro et al., ${ }^{2,3}$.

\section{Conclusions}

Dynamic test performed to the composite based on coconut fiber-polypropylene shows that the increase in fiber content reduces the Loss Factor, Storage Factor and Loss Modulus. This behavior can be attributed to lower elastic modulus of the fiber, as compared to the PP matrix.

The elastic modulus values obtained by the half-power band method and the stress-strain test were compared. Values were similar for those samples containing up to $15 \% \mathrm{vol}$ of coconut fiber. Above that, the values were remarkably

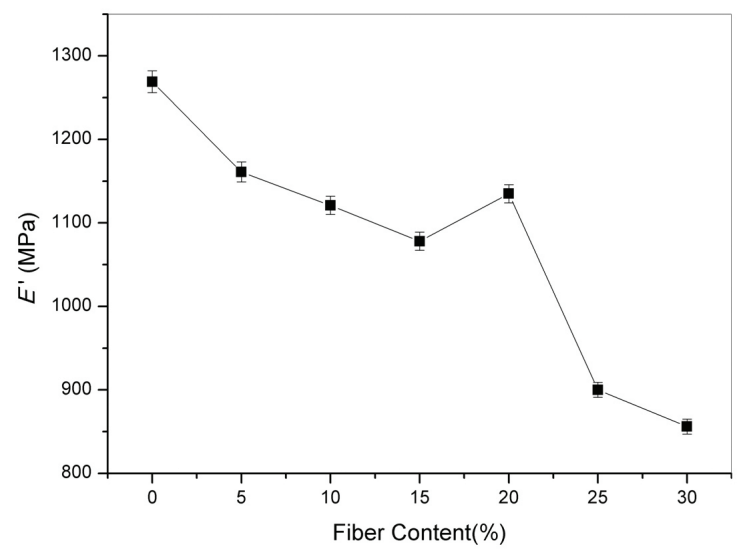

Figure 7. Storage modulus as a function of coconut fiber content.

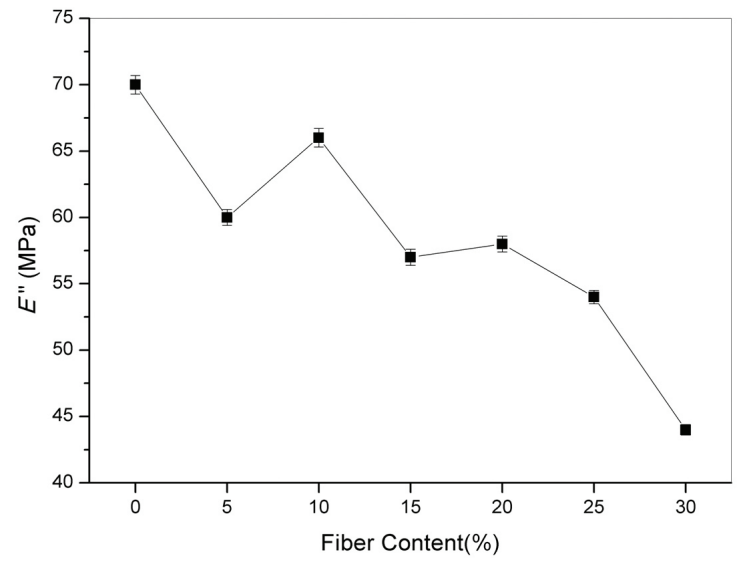

Figure 8. Loss modulus as a function of coconut fiber content.

distinct due to lower interaction between the fiber/matrix, reducing the reinforcement effect on the polymer.

In this way, the Dynamic Method used in this study to measure the elastic modulus for coconut fiber-PP composites was revealed as a non-destructive method and a very reliable test. The vegetal fiber-polymer matrix composite usually presents lower mechanical strength than polymeric composite based on inorganic fibers, such as glass, carbon or aramid, but it presents much lower cost due to the natural source of these materials. These composites can be applied in nonstructural elements, such as fence panels and linings.

\section{Acknowledgements}

The authors are thankful to Coordenação de Aperfeiçoamento de Pessoal de Nível Superior (CAPES), Conselho Nacional Desenvolvimento Científico e Tecnológico (CNPq), Fundação de Amparo à Pesquisa do Estado de Minas Gerais (FAPEMIG) and to Companhia Energética do Ceará (COELCE) for financial support. 


\section{References}

1. Gelfuso MV, Da Silva PVG and Thomazini D. Polypropylene Matrix Composites Reinforced with Coconut Fibers. Materials Research. 2011; 14(3):360-365. http://dx.doi.org/10.1590/ S1516-14392011005000056

2. Monteiro SN, Terrones LAH, Lopes FPD and D'Almeida JRM. Structural characteristics and properties of coir fiber wastes reinforced polymeric composites. In: Proceedings of the International Congress on Materials; 2005; Cartagena. Cartagena; 2005. p. 1-6. PMid:16051027.

3. Monteiro SN, Terrones LAH, Carvalho EA and D'Almeida JRM. Efeito da interface fibra/matriz sobre a resistência mecânica de compósitos poliméricos reforçados com fibra de côco. Revista Matéria. 2006; 11(4):395-402. http://dx.doi. org/10.1590/S1517-70762006000400005

4. Hariharan ABA and Khalil HPSA.Lignocellulose-based Hybrid Bilayer Laminate Composite: Part I - Studies on Tensile and Impact Behavior of Oil Palm Fiber-Glass Fiber-reinforced Epoxy Resin. Journal of Composite Materials. 2005; 39(8):663667. http://dx.doi.org/10.1177/0021998305047267

5. Scherzer H, Dahlke B and Poltrock R. Larbig H.Natural Fiber Reinforced Foams Based on Renewable Resources for Automotive Interior Applications. Journal of Cellular Plastics. 1998; 34(4):361-379.

6. Nashif AD, Jones DIG and Henderson JP. Vibration Damping. New York: John Wiley \& Sons; 1985.

7. Lopes EMO. Um Estudo da Precisão do Método da Viga Vibrante Aplicado à Determinação das Propriedades Dinâmicas de Elastômeros. [Dissertação]. Florianópolis: Universidade Federal de Santa Catarina; 1989.

8. Zener C and Siegel S. Elasticity and Anelasticity of Metals. Journal of Physical Chemistry. 1949; 53(9):1468-1468. http:// dx.doi.org/10.1021/j150474a017

9. Jones D. Handbook of viscoelastic vibration damping. Chichester: John Wiley \& Sons; 2001.

10. Mandal NK, Rahman R and Leong MS. Experimental study on loss factor for corrugated plates by bandwidth method.
Ocean Engineering. 2004; 31(10):1313-1323. http://dx.doi. org/10.1016/j.oceaneng.2003.08.003

11. Ramesh TC and Ganesan N. Orthotropic Cylindrical Shells With A Viscoelastic Core: A Vibration And Damping Analysis. Journal of Sound and Vibration. 1994; 175(4):535-555. http:// dx.doi.org/10.1006/jsvi.1994.1344

12. Castello DA. Modelagem e Identificação de Materiais Viscoelásticos do Domínio do Tempo. [Tese]. Rio de Janeiro: Universidade Federal do Rio de Janeiro; 2004.

13. Faísca RG. Caracterização de Materiais Viscoelásticos como Amortecedores Estruturais. [Tese]. Rio de Janeiro: Universidade Federal do Rio de Janeiro; 1998.

14. Rao SS. Vibrações Mecânicas. São Paulo: Pearson Prentice Hall; 2008.

15. Silva RP. Desenvolvimento de Metodologias para Caracterização de Materiais Viscoelásticos em Baixas Frequências. [Dissertação] Rio de Janeiro: Universidade Federal do Rio de Janeiro; 2007.

16. Dimarogonas AD. Vibration Engineering. New York: West Publishing Co.; 1976.

17. Rosen SL. Fundamental principles of polymeric materials for practicing engineers. New York: Cbi Pub Co.; 1971.

18. Rozman HD, Tay GS, Kumar RN, Abubakar A, Ismail H and Ishak ZAM. Polypropylene Hybrid Composites: A Preliminary Study on the use of Glass and Coconut Fiber as Reinforcements in Polypropylene Composites. Polymer-Plastics Technology and Engineering. 1999; 38(5):997-1011. http://dx.doi. org/10.1080/03602559909351627

19. Monteiro SN, Rodriguez RJS, Lopes FPD and Soares BG. Efeito da incorporação de fibras de coco no comportamento dinâmico-mecânico de compósitos com matriz poliéster. Tecnologia em Metalurgia e Materiais. 2008; 5(2):111-115. http://dx.doi.org/10.4322/tmm.00502009

20. Freire E, Monteiro EEC and Cyrino JCR. Propriedades Mecânicas de Compósitos de Polipropileno com Fibra de Vidro. Polímeros. 1994; 25-32. 